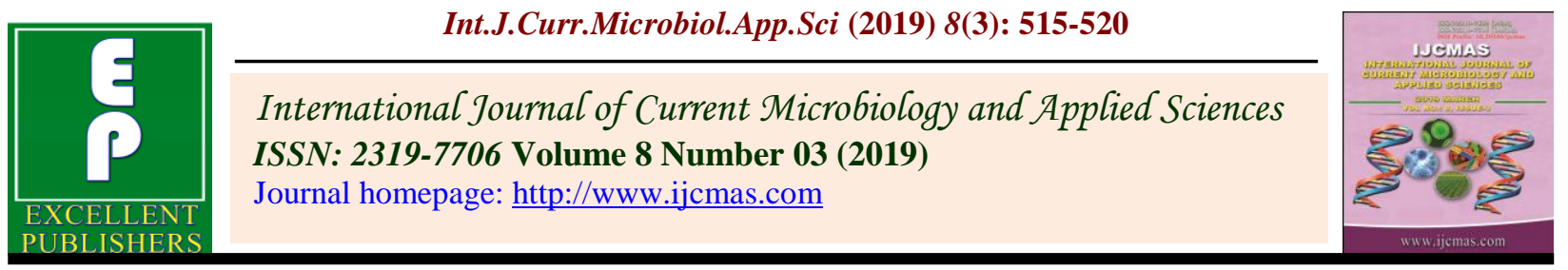

Original Research Article

https://doi.org/10.20546/ijcmas.2019.803.062

\title{
Extended Spectrum Beta-Lactamase Producing Infections Associated with Progressive Periodontitis
}

\author{
Fahad H. Alqahtani ${ }^{1}$, Haya Mansour Al Yousef ${ }^{2 *}$ and Al Yousef, Ali Sulaiman ${ }^{3}$ \\ ${ }^{1}$ BDS.AEGD.ARD, Restorative Dental Consultant, Moustashark Dental Center, \\ Riyadh, Saudi Arabia \\ ${ }^{2}$ College of Dentistry, King Saud University, Riyadh, Saudi Ariabia \\ ${ }^{3}$ College of Dentistry, Al Majmah University, Riyadh, Saudi Arabia \\ *Corresponding author
}

Keywords

Aggressive periodontitis, ESBL producers,

Subgingival microbiota,

Anaerobic ESBL producing bacteria

Article Info

Accepted:

07 February 2019

Available Online:

10 March 2019

\section{A B S T R A C T}

Aggressive periodontitis ( $\mathrm{AgP})$ is one of the most severe forms of periodontal diseases. Extended Betalactamas producing (ESBL) bacteria don't respond to antibiotic treatment and cause failure of clinical practice. There is limited knowledge is available about incidence of ESBL bacteria in AgP. Therefore, the main aim of this study was to evaluate prevalence of ESBL bacteria in $\mathrm{AgP}$. The present study was conducted for a period of one and half year from March 2017 to October 2018 at a tertiary care teaching hospital. Subgingival plaque samples were collected AgP patients. Samples collected from the four deepest periodontal pockets in each patient were pooled in pre-reduced transport fluid and examined by culture. A total of 80 samples were collected from 80 patients yielded 163 isolates, out of which $28 \%$ were ESBL producers. Bacteroides fragilis was the most common organism followed by Fusobacterium species. ESBL producing anaerobic bacteria are found exits in $\mathrm{AgP}$ periodontitis cases. The current study identified $28 \%$ of the isolates to be ESBL producers. Therefore drug susceptibility testing is essential before starting the treatment and in emergency cases drugs should be chosen to cover ESBL producers.

\section{Introduction}

Aggressive periodontitis is a form of periodontitis characterized by rapid and severe periodontal destruction in otherwise young healthy individuals. The etiology of periodontitis is very complex including the dental biofilm, which triggers the immunoinflammatory response in a susceptible host. This interaction leads to the destruction of the periodontal tissues $(1,2)$. Pathogenic bacteria are the primary etiology agents in the 
pathogenesis of periodontitis. The oral biofilm is very complex and count for over 700 species, however only some microorganisms have been specifically associated with periodontal diseases (2). These microorganisms do not suffice to advance the disease. Indeed, the host immune response modules the evolution of the disease toward destruction or cure (3). The role of these bacteria in the pathogenesis of the human periodontitis is based on their high frequency of isolation, the ability to adhere to epithelial cells, the ability to produce numerous virulent factors like the extracellular matrix proteins, protease, collagenase, endotoxin, bacteriocins, hemotactic inhibitors, leucotoxins, cytotoxins, toxic metabolic substances ( $\mathrm{H} 2 \mathrm{~S}$, putricines), immunosuppressive proteins, etc. $(4,5)$.

The majority of periodontal pathogens are Gram-negative and strict anaerobe, acting in synergy. These bacterial species produce a wide variety of virulent factors enabling them to colonize subgingival sites, to resist the defense mechanisms of the host and to cause periodontal tissue destruction (6).Among these bacterial species which are associated with aggressive periodontitis extended spectrum beta-lactamase (ESBL). In fact ESBL infections are challenging as it didn't respond to empirical treatment and can cause serious complications. Therefore in medical practice, a definition of ESBL infection requires a combination of both clinical manifestations and laboratory findings (7).

Antimicrobial resistance surveillance is necessary to determine the problem and to guide empirical selection of antimicrobial agents for treating infected patients. The aim of this study was to determine the current prevalence, clinical and laboratory profile of ESBL producing infections isolated from patients with progressive periodontitis at King Khalid Hospital, Hafar Elbatin, Saudi Arabia.

\section{Materials and Methods}

\section{Study setting}

This cross-sectional study was performed at Central Hospital, Hafr Al-Batin, and Saudi Arabia between March 2017 and October 2018.

\section{Study participants}

Inclusion criteria for this study were newly diagnosed patients as $\mathrm{AgP}$ in Periodontology outpatient department. The exclusion criteria were patients medically compromised, or having received periodontal or antibiotic treatment within the preceding 6 months, patients under orthodontic treatment pregnant women or during lactation, and patients who need antibiotic prophylaxis before screening.

\section{Bacterial sampling and analysis}

Sampling collection was done within week after clinical examination, by means of pooled subgingival samples from each patient. Subgingival plaque samples were collected from four deep sites, one per quadrant, from each patient. Supragingival plaque, located in direct proximity to sample sites, was carefully removed using a scaler and cotton gauze. A sterile, absorbent paper point was gently inserted into the apical extent of the periodontal pocket (sulcus). After 20 seconds, the papers were pooled in a tube containing $1.5 \mathrm{ml}$ of reduced transport fluid (RTF) medium (8). All plaque samples were collected by the same examiner.

\section{Microbiological procedures}

Samples were transported to microbiology laboratory in fluid thioglycollate medium. Samples were immediately processed. Modified gram staining for anaerobes was performed and inoculated on Brucella blood 
agar supplemented with hemin and vitamin $\mathrm{K}$, Kanamycin Vancomycin Laked Blood Agar, Bacteroid bile esculin agar and Brain heart in fusion agar and incubated at $37^{\circ} \mathrm{C}$ in McIntosh Fildes jar. The method used for obtaining anaerobiosis in the jar was 'internal gas generating system" described by Vaidhyalingam and Laxminarayana (9). After 72 hof incubation culture growth was noted for morphology, pigment, pitting, hemolysis and fluorescence. And also preliminary tests such as gram stain, spot indole and catalase tests were performed. Further identification was made with the help of identification discs such as kanamycin (1 mg), vancomycin (5 $\mu \mathrm{g})$, colistin $(10 \mu \mathrm{g})$, sodium polyethanol sulfonate disc and nitrate disc. All the organisms isolated and identified were tested for the production of betalactamase by chromogenic Nitrocefin disc method (11)

\section{Nitrocefin disc method}

Nitrocefin disc was inoculated with a small portion of growth from Brucella blood agar plate and observed for a change in color from yellow to red. Disks which did not show color change within $10 \mathrm{~min}$ at room temperature were additionally incubated for $60 \mathrm{~min}$ at $37^{\circ} \mathrm{C}$. A test was considered positive when yellow color turned to pink/red.

\section{Results and Discussion}

A total of 80 patients were enrolled during the study period. The patients aged 20 to 60 years with male $56(34 \%)$ to female 107 (66\%). Totally 80 samples yielded 163 isolates of which 153 were anaerobes. Out of 153 organisms 43 (28\%) were ESBL producer and $110(72 \%)$ were non ESBL producing organisms. Only anaerobic Gram negative bacilli showed ESBL production. Bacteroides fragilis was the most common organism followed by Fusobacterium spp. The ESBL producing organisms isolated in the present study are shown figure 1. Periodontitis is one of common diseases. There are vast diversities of human bacteria pathogen that are present in the mouth, and each individual has his or her own unique oral flora; but the composition of the oral flora determines the susceptibility of tooth decay. The microbiological flora of oral cavity is diverse and varies in normal and disease condition. ESBL are major concern in orofacial infections.

This study is cross-sectional study to identify the presence of ESBL bacteria in progressive periodontitis. Presence of ESBL microorganisms has significant effect on treatment strategy.

The finding in this study showed that $28 \%$ of isolates were ESBL producers. Quite similar results were obtained by and Iwahara et al., who identified 36\% (11) and in another study carried out by Walker identified $36 \%$. (12). On other hand other studies showed higher rate of incidence of ESBL in human periodontitis such as studies performed by Rams et al., identified $52.1 \%$ and Patel identified 69\% ESBL producers $(13,14)$.

The present study showed that Bacteriods fragilis was the most common ESBL producer (70 \%), however as per the Clinical Laboratory Standard Institute (CLSI) guidelines $B$. fragilis organism should not be tested and reported as ESBL. For all practical purpose they are considered as ESBL (10).In the current study, they were included for research purpose and all of them showed positive reaction on nitrocefin disc. In the present study other ESBL producing were identified Fusobacterium spp (21\%) followed by Fusobacterium nucleatum (4\%), Porphyromonas spp (3\%) and Prevotella intermedia (2\%). Other studies reported inconsistent results as Prevotella spp was the most common $\beta$-lactamase producing organism $(11,12,13,14)$. This can be 
explained by the fact that resistance rates vary depending site of hospital and also within the species of organisms. Penicillin resistance can be common anaerobic among on Bacteroides, but is not predictable. The increasing and prevalent antibiotic resistance among anaerobes is correlated with discovery and characterization of multiple, transferable resistance determinants corresponding to their respective resistance phenotypes. In addition heavy, irrational and indiscriminate use of antibiotics may result in selection and transfer of these resistance determinants (15).

Fig.1 Percentage of ESBL producing bacteria



Many different types of $\beta$ lactamase enzymes have been identified in the literature. But the main two types are Ampc Blactamase and ESBL enzymes. Ampc ßlactamase are encoded by the genes on the chromosomes and are inducible (15). ESBL are encoded by genes on the plasmid and are transferable (16). Bush and Jacoby have classified ßlactamase enzyme into two groups based on the function and molecular basis depending on amino acid sequence (17). Chromogenic cephalosporin (nitrocefin) disc method is the recommended method by CLSI for ESBL detection(10). Iwahara et al., (11) In their study observed $31 \%$ of Prevotella spp to be ESBL producers by nitrocefin disc method. Further, it was confirmed by detecting CfxA and CfxA2 gene by real time polymerase chain reaction for all 48 (31\%) $\beta$-lactamase positive Prevotella strains. Hence, nitrocefin disc method can be used as sensitive screening method for $\beta$-lactamase production in developing countries where facilities for molecular methods are not available. By molecular diagnostic methods, various susceptible genes have been identified in the literature for $\beta$-lactamase production namely cfxA, cfxA2, cfxA3, bla (TEM), bla (SHV), bla (OXA), bla (ampC), bla(cfxA) and bla(cepA/cb1A).(11,18) The studies have also concluded that there are many different genetic determinants of $\beta$-lactamase production which still needs to be characterized. (18). ESBL play an important role in mixed infections. First, they cause pathogenicity by inhibiting the drugs. Secondly, they transfer the plasmid genes and render other bacteria to become resistant and 
lastly they release the enzymes to the environment and neutralize the drug. There are various studies available in the literature to support the mechanism of ESBL (19). Some anaerobes are resistant to ßlactam antimicrobial agents by mechanisms other than ßlactamase production. Therefore, a negative $\beta$ lactamase test does not necessarily assure susceptibility to these antimicrobials (10).

However, there is lot of research about ESBL in the literature, epidemiological data on ESBL in periodontitis in Saudi Arabia is still lacking. More studies of are required to accurately detect and identify these strains in different parts of Saudi Arabia.

\section{References}

1. Philstrom BL, Michalowicz BS, Johnson NW. Periodontal diseases. Lancet. 2005; 366:1809-20.

2. Sanz M, van Winkelhoff AJ. Periodontal infections: understanding the complexity. Consensus of the Seventh European Workshop on Periodontology. J Clin Periodontol. 2011; 38 Suppl 11:3-6.

3. Socransky SS, Haffajee AD. Periodontal microbial ecology. Periodontol 2000. 2005; 38:135-87.

4. Schenkein HA. Host responses in maintaining periodontal health and determining periodontal disease. Periodontol 2000. 2006; 40:77-93.

5. Socransky SS. Relationship of bacteria to the etiology of periodontal disease.J Dent Res. 1970; 49:203-22.

6. Curtis MA, Slaney JM, Aduse-Opoku J. Critical pathways in microbial virulence. J Clin Periodontol. 2005; 32 Suppl 6:2838.

7. Freedman AL. Urinary tract infection in children. Urol Dis Am J. 2002; 13:44190 .
8. Syed SA, Loeshe WJ. Survival of human dental plaque flora in various transport media. ApplMicrobiol. 1972; 24:638-44.

9. Vaidhyalingam K, Laxminarayana CS. Internal gas generator system suitable for creating anaerobiosis. Indian J Surg. 1980;42:154-9.

10. Sixth Informational Supplement M11A6.Wayne, USA: CSLI; 2004. Clinical and Laboratory Standards Institute Methods for Antimicrobial Susceptibility Testing of Anaerobic Bacteria; Approved Standard.

11. Iwahara K, Kuriyama T, Shimura S, Williams DW, Yanagisawa M, Nakagawa $\mathrm{K}$, et al., Detection of cfxA and cfxA2, the betalactamase genes of Prevotella spp., in clinical samples from dentoalveolar infection by real-time PCR. J Clin Microbiol. 2006;44:172-6.

12. Walker CB, Tyler KZ, Low SB, King CJ. Penicillin degrading enzymes in sites associated with adult periodontitis. Oral Microbiol Immunol. 1987; 2: 129-31.

13. Rams TE, Degener JE, van Winkelhoff AJ. Prevalence of ßlactamase producing bacteria in human periodontitis. $\mathrm{J}$ Periodontal Res. 2013;48:493-9.

14. Patel M. The prevalence of beta lactamase producing anaerobic oral bacteria in South African patients with chronic periodontitis. SADJ. 2011; 66: 416-8.

15. Bush K, Jacoby GA, Medeiros AA. A functional classification scheme for betalactamases and its correlation with molecular structure. Antimicrob Agents Chemother. 1995;39:1211-33.

16. Knothe H, Shah P, Krcmery V, Antal M, Mitsuhashi S. Transferable resistance to cefotaxime, cefoxitin, cefamandole and cefuroxime in clinical isolates of Klebsiella pneumoniae and Serratia marcescens. Infection. 1983;11:315-7.

17. Bush K, Jacoby GA. Updated functional classification of betalactamases. 
Antimicrob Agents Chemother. betalactamase genes insubgingival 2010;54:969-76.

bacteria from patients with refractory

18. Nwaokorie FO, Ogunsola FT, Coker AO.

Betalactamase production in anaerobic periodontitis. FEMS Microbiol Lett. 2005; 242: 319-24. bacteria. Rev Infect.2010;1:172-9.

19. Handal T, Olsen I, Walker CB, Caugant DA. Detection and characterization of

20. Brook I. The role of betalactamase producing bacteria in mixed infections. BMC Infect Dis. 2009; 9:202.

\section{How to cite this article:}

Fahad H. Alqahtani, Haya Mansour Al Yousef and Al Yousef, Ali Sulaiman. 2019. Extended Spectrum Beta-Lactamase Producing Infections Associated with Progressive Periodontitis. Int.J.Curr.Microbiol.App.Sci. 8(03): 515-520. doi: https://doi.org/10.20546/ijcmas.2019.803.062 